\title{
THE MEANING OF ORIGINALITY IN ARCHITECTURE AND HOW CAN IT BE MEASURED
}

\author{
Vian A. Shareef \\ Department of Architecture, Faculty of Engineering, Koya University, \\ Koya KOY45, Kurdistan Region - F.R. Iraq. \\ vian.ahmed@koyauniversity.org
}

\section{Original Scientific Paper doi:10.5937/jouproman6-17462}

\begin{abstract}
Meaning and different definitions for originality, meaning of originality in architecture, and the way of measuring it has been investigated in this research, which help researcher to compare between every two design product by using the applied criteria, in a straightforward method. Also, this research has determined the methods that architect can use to produce and increase the original idea in a research. Additionally, a number of samples have been taken as case studies to compare and evaluate originality in Architecture.
\end{abstract}

Key words: Originality, originality in architecture, measuring originality in architecture, creativity, innovation.

\section{Introduction}

The word Originality means combining old ideas and methods together in a new fashion and way rather than meaning thinking about something that was never done and thought before. Originality is a type of mysterious and wonderful thing that is really key in order to the support of societies which means without originality all the inventions as well as innovations are impossible to be achieved. Moreover, the most vital characteristic regarding originality is that it can always consist something useful and new. On the other hand, originality must be requiring as the sole identity of the building with actual layers of its fabric as it ages [26].

Also, originality means, in the way of keeping the useful parts of the old ideas and adding in new and creative things. Additionally, originality could surely keep the old and valuable aspects of the old ideas as well as adding new ideas, which will help us for more efficiency; therefore the case is true in almost all the inventions and innovations. Consequently, originality can be defined as the outcome of improving the old concepts and aspects. However invention and innovation are frequently made by inheriting components of old ideas and systems [5].

\section{Literature review}

\subsection{Definitions for originality}

According to random house Webster's college dictionary the originality is "the state or value of being original". Also, the capability to express or meditate oneself in specific style and an independent. In addition, uniqueness or brilliance, inventive capacity, presentation or technique. However, Kernerman English Learner's Dictionary well-defined originality by means of: the quality of being dissimilar and exclusive everything else.

\section{- Originality mean:}

It's accurate that the meaning of originality is not permanently somewhat new. Nonetheless it can be old feelings showed in innovative methods. It means that Originality derives from inventiveness, larger viewpoint and cleverness. 
On the other hand, it can be finding of preexisting concepts and views which are offered with a completely diverse point of view [6].

However, originality of an idea can be refereed only if it is known that how the idea came into existence. Also, conclude that originality is continually around re demonstrating the existing notions \& giving them. On the other hand, an idea can actually be a first of its kind from scratch or it can be a remodelling of existing ideas. Additionally, it can be believed that innovation has its own scopes and faces. Also it is based upon each single case whether that exact part of gem has to be known as original [5].

Nonetheless, about to the originality in a country such as United States in the year 2008, the Tenth Circuit applied these extended-standing guidelines of originality to digital prototypes of physical objects; in this occasion, Toyota automobiles regarding the necessity of free creation [13].

In addition, there must be creativity in art. Initially: in relations of quantity. It is believed that there must be just one of somewhat to be art. There is the problem of mass-invention to consider. [17].

\section{- Creativity and Innovation}

The meaning of Inventiveness is the generation of different concepts either new techniques of observing at current problems, or of sighting different chances, possibly by variations in marketplaces or exploiting evolving skills [17]. See figure 1.

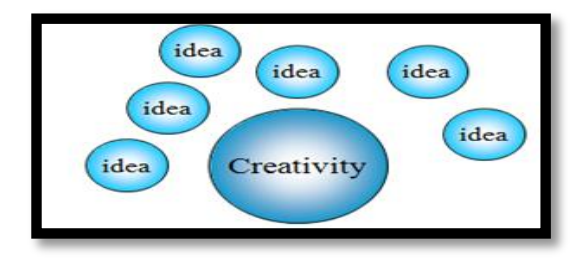

Figure 1. Creativity idea

Nonetheless, the permitted Description of "Creativity" is "Creativity," such as "originality," it is matter to largely unequal interpretations. [23].

On the other hand, Dictionaries describe 'innovation' by means of 'presenting something new': the Latin stem 'innovate' denotes to restarting or altering, and it is resulting from 'Novus', the meaning is 'new' [17]. In addition, Amabile et al. (1996) defined innovation and its relation to creativity:" All innovation begins with creative ideas...creativity by individuals and teams are a starting point for innovation; the first is necessary but not sufficient condition for the second".

Consequently, 'Design' is what connects innovation and inspiration. It forms notions to become attractive propositions and a realworld for clients or consumers. It might be defined as originality deployed to a precise conclusion. [7]. See figure 2. $\mathrm{a}$ and $\mathrm{b}$

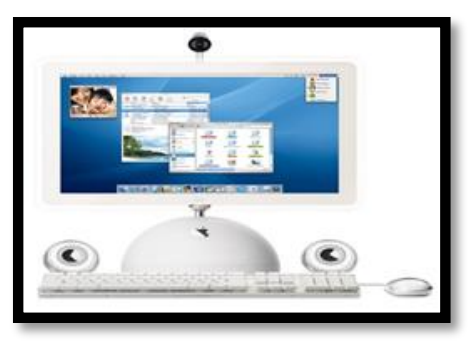

Figure 2.a: Apple G4 [7]. 


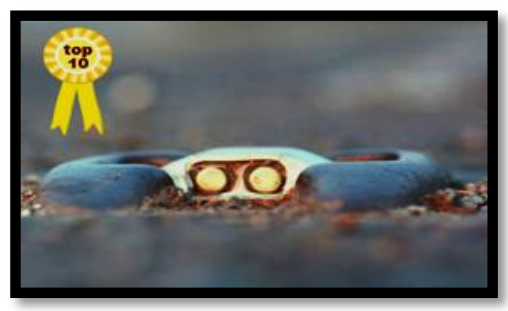

Figure 2.b: Innovative design : product design [7].

\subsection{Originality in architecture:}

\section{- Post modernism architecture:}

It is clear that post modernism architecture breached totally earlier architectural ideas in addition, it became more specific. Such as, in this style regularity and decorations are vanished. Furthermore, this architectural style removed the constructive construction and architectural individuality. At that time, deconstruction architecture appeared [8].

\section{- Is originality continually desirable or feasible in architecture?}

Architecture is needed to be original as an art, or it should struggle to be at least. In the practice of architecture, one understands that many determinants or conditions frequently intervene; therefore, the consequential project is a really far from it [22].

\section{- Tradition and originality}

Why should we quit from requesting the legitimate right of utilizing the concepts such as, inventiveness originality and creativity? It seems that the practice of classic and traditional architecture benefits from the most imposing sum, not only of the historical evidences, but of the new and the contemporary demonstration of inspired creativity or impressive originality [3]. See figure 3 .

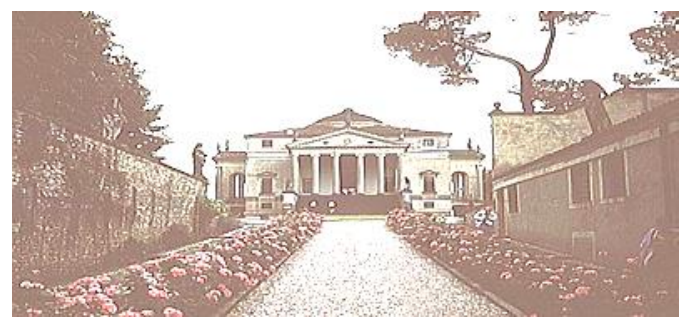

Fig 3. Villa Rotunda, Vicenza, by Andrea Palladio.

In fact it should be admit over again the 'original' sense of innovation which contains in re-evaluating the basis of something in its source. Also, Originality meaning would thus be the very spirit of the original polarity of nature and custom...Rather than examining the limitations of notional catastrophes [16].

In addition, it can be seen from figure 4 . The architecture's origin in wooden construction [20].

Moreover, the term origin means that what something is, like it is, and it could be call nature or spirit. Additionally, the source of something is the basis of its nature. In another meaning, Originals are forms which greatest truly reflect the forms of source [4].

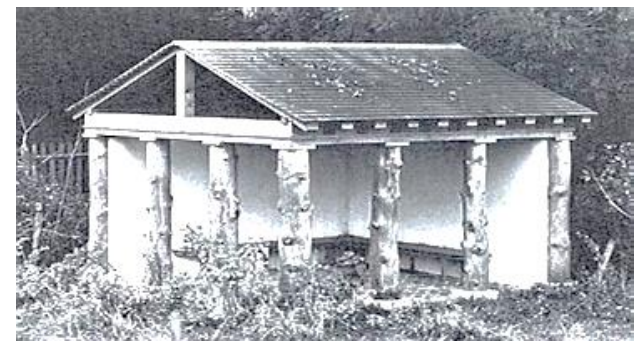

Fig 4. Originals and origin: Garden Pavilion, by Quinlan Terry.

\section{- The role of originality in architecture:}

It can be said that, the role of novelty in architecture continually has been related to its importance inside an exact social context. 
Also, originality does not imply ignoring the previous and ignoring the earlier does not assurance originality. One has only to travel back less than a century, so as to be persuaded [12].

On the other hand, in regarding to the mechanisms of architect Gehry on originality, creativity and getting one's technique in the finish, it's clear that, Frank O. Gehry received global renowned for his project of the Guggenheim museum in Bilbao (1997) [7].

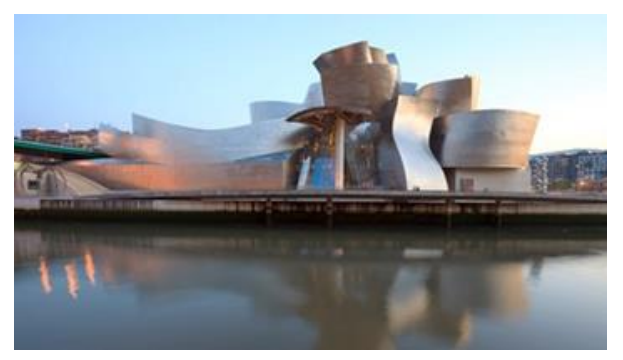

Fig 5. Guggenheim museum

In addition, as can be revealed in figure 5 , Gehry deliberated the sense of balance he seeks to achieve between the official limitations of his architectural practice, intuitive side of his art and the imaginative. Also the importance of conveying "feeling" over his work. On the other hand, he has been used models as his "main design tool" [7]. As Frank O. Gehry said. "If it looks like something I've done before, I discard it."

Finally, Gehry pointed out to his design for the Loyola Law School in Los Angeles, so as to demonstrate the peculiar imaginative dynamic between architect and artist. In addition, his original strategy for the project named for a sequences of pillars, without capitals or roots, so as to stand straight in front of the structure or building and suggesting traditional rooms of justice [7].
- What architects can do to produce original ideas :

There are a lot of methods that, Architect can use to achieve the original concept in his project, these techniques are different from architect to other according to their back ground, an experiences and several other factors (Shareef, 2018).

Also, many architects as well as other artists dread originality, because they don't have it in their works or sometime it is doubtful an easy fake to appeal attention. Actually nothing in art is totally and severely original with its inventor. They have been inspired by several things, past and present, occasionally imitating them but continuously eventually integrating them if they are actual artist [18].

But, the imaginative architects must be careful of subjecting their works to a ,personal style' or ,trademark'. His script will have his own personal features. On the other hand, all their works deserves to become their own form and chic. Therefore, all of their works will be jointly and unique also they will signify their architect's originality [18].

\section{- Methods that can increase original ideas in architecture:}

Architects can use geometries so as to increase original concept, because the source of which are unidentified, and discoveries inspiration in the ,free-forms' of nature. These bases belong to no man till he makes them their personal in their unique and individual mechanisms. On the other hand, the natures of resources, the innovative works of others, principles, approaches, confidence, exposés of discipline and more than these gives them backgrounds to grow. Furthermore, natural innovation will be indicated by their activities since they are evidently original [2]. 
At the same time architectures will connect the outside-in formalism of the constant regulation of concrete structures and steel with their monotonous, subsequent rhythmic sterility and plug-in systems. On the other hand, necessities, surplus, methods and technological information will elaborate original architects to yield newly-beautiful design-structures of architecture as directly as the composer of music reaches us, without performance or interpretation by others, via the new medium of electronic music. This will permit the architect to recognize his work and to perceive of, through a number of processes [2].

\section{Methodology}

\section{1 research aim}

The aims of this research are:

1. To understand the meanings and definitions of originality in general.

2. To identify the meaning of originality in architecture and discussing the best method for measuring originality in architecture.

3. To underline the criteria that can be used for measuring originality generally and particularly in architecture.

4. To study and discuss the methods that architect can increase and produce original idea in his work by using it.

\subsection{Research questions}

1. What are the meanings and definitions of originality and how can it be measured?

2. What are the meaning of originality in architecture and how can it be measured?
3. How architects can invent and increase original idea in their profession, and what are the methods of implementing it?

\subsection{Research case studies}

\section{The criteria and variables for measuring originality}

1. The place properties buildings and its relation with the shape properties

2. Shape properties of buildings and its relationship with the past.

3. Aesthetic properties.

4. Functions and effects.

5. Ergonomic properties

6. 6-Meaning (design concept and ideology)

7. Innovative, unique and creative

8. Operational properties

9. Functionally determined properties.

10. Interesting.

11. Advanced technology.

12. Architectural articulation

13. Implicit connotative symbolism

14. Abstraction.

15. The iconicity of the building or structure

16. Memorable and distinctiveness

17. Representation or symbolic property

18. (Attracting attention - pragmatic.)

\section{Case study 1:}

Comparing between (two chair design products) as shown below:

A-Chair from the infinity furniture collection by Tangle Creations Steel. And

B-Hill house chairs Italy late 20th century. 


\section{A- Chair from the infinity furniture collection by Tangle Creations:}

Tangle creations founder Richard X Zawitz, in common with Pierandrei Associati, Baci \& Abbracci and Techno delta have linked together to co-produce and launch a single line of sculpture-based furniture and an inventive lighting system based on Zawitz's Infinity Art. As well, Richard X Zawitz reported that: "I finally reveal the first true marriage between lighting and sculpture with furniture".

Additionally, as can be seen from Figure 6. (a) And (b), Mr. Zawitz has advanced his mainstream art-based products far from its first origins such as a hand-held, free-flowing movable sculpture piece, crossing over into new mediums like metal, wood, stone, and shared media across new repetitions of his creative Statue of Infinity stainless steel sculpture [21].

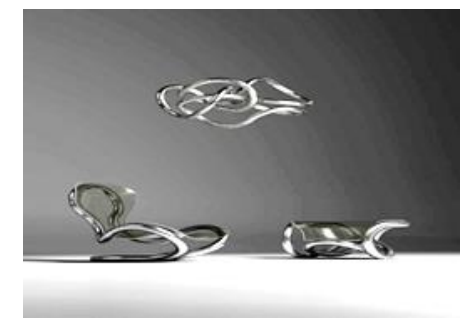

Figure 6. a: Chair from the infinity furniture collection

By Tangle Creations Steel, [21].

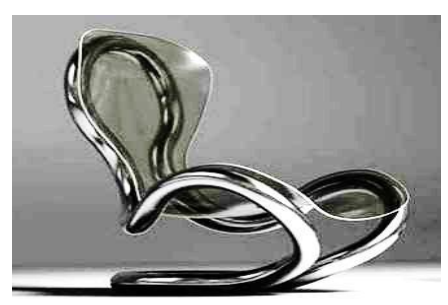

Figure 6. b: Chair from the infinity furniture collection

By Tangle Creations Steel, [21].

\section{B- Hill House Chairs Italy late 20th century:}

Hill House Chairs in Italy in the last decades of twentieth century a couple of Mackintosh
Hill House ladder back chairs and Stained black ash wood frames with seats upholstered in Mackintosh pink silk velvet which has been shown in figure 7.Also, Cassina has crafted under supervision of the Estate of Charles Rennie Mackintosh such as displayed by serial number on each chair and a stamped signature [10].

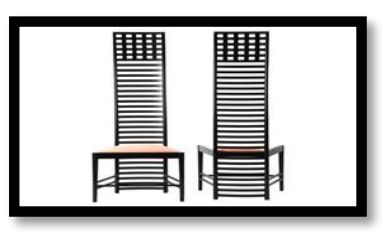

Figure. 7 Hill house chairs Italy late 20th century

Design by Costas Voyatzis

\section{C- Conclusions case study 1}

From the two design products mentioned previously, the researcher identified that the chair a- chair from the Infinity Furniture Collection is more iconic, symbolic, memorable, distinctive, innovative, unique and creative according to its shape. The shape of the chair is made from one piece and it's more simple and easy to deal with. It is simply more technician a mixture of steel and glass in comparison to the chair b- Hill House Chairs Italy that is a stained black ash wood frame with seats upholstered in Mackintosh pink silk velvet ordinary quiet common and similar to other chairs .

Also the chair(a) is aesthetically really nice and its material consist of steel and glass, also in terms of colour it is a bright black colour which makes it stand out and more attractive compare to chair (b). On the other hand, the chair (a) seems to be more expensive and interesting than the chair (b). Moreover, the chair (a) Seems to be built by an advanced technology and technique in comparison to the chair (b) that is more common and ordinary one. 
Furthermore, it is noticeable that chair (a) is an architectural articulation compare to the chair (b).

\section{Case Study 2 \\ Comparing between (a-Burj-Al Arab and b-Emirates Twin Towers).}

\section{A- Burj-Al-Arab in Dubai:}

Probably Burj -Al- Arab is the most iconic building in Dubai, the world's first 7star hotel, it has been completed in 1999.On the other hand, the hotel was designed by Tom Wright of Atkins and it was first conceived in 1993.It can be understood from figure 8 . The Burj has been designed to be marketed and an icon as a symbol of Dubai [24].

At that time Dubai was early in its development, this helped the Burj-al-Arab gain this position without too much rivalry. Nonetheless the factual testament to its originality status is its capability to continue one of the strongest symbols of Dubai. Also, there are a numbers of different features of the design that contributes to the originality status of this building. On the other hand, the thing that isolates it from any other developments on the mainland is the Burj-alArab's place on an island, permitting clear views of the building and appealing attention it's always visible [24].

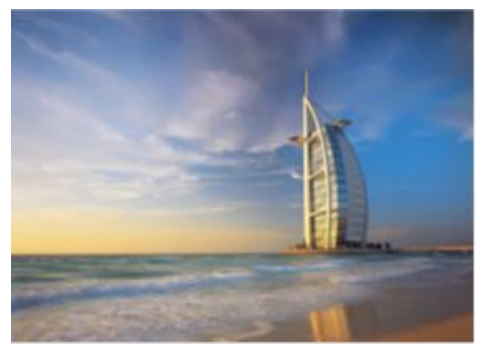

Fig. 8 the Burj-Al-Arab
In addition, the sheer scale of the hotel makes it impressive; it stands at $321 \mathrm{~m}$ tall and has the Duba's tallest atrium at $182 \mathrm{~m}$. Furthermore, the Burj-al-Arab has numerous pioneering characteristics that required the latest technology, for example the artificial island is built from particularly designed hollow concrete blocks which absorb the wave.

Also, it can be seen that Al Muntaha cafeteria meaning "highest" in Arabic beams out a long distance $200 \mathrm{~m}$ above the sea. This unbelievable achievement of engineering only adds to the long list iconic topographies this construction has [24].

Additionally, when designing the burj- al- arab wright supposed he had to follow this ides: "We looked at the other buildings around the world that are symbols to see what they had in common. We found that they were all totally unique in shape and they all have a simple easily recognizable form. We decided that the test to determine if a building is symbolic is, if you can draw it in 5 seconds and everyone recognizes it" [11].

Furthermore, as a design concept Wright used the old-style (Arabic boat) to stimulate the form of the building which can be seen in figure 9.Through the great double skinned, Teflon covered woven cut-glass fibre screen mimicking a sail billowing in the breeze which reflects Dubai's maritime inheritance joint with modern design moving into the future[11].

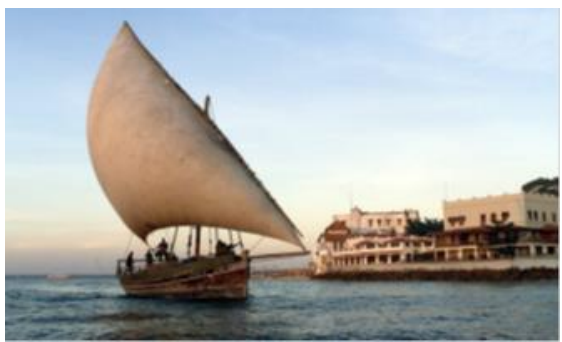

Figure 9: Arabic boat 
However, the Burj-al-Arab signifies other parts of Dubai's character; also it is a sign of Dubai's changeover from its inheritance to its Future. In addition, its location out in the sea incomes that it stands proud, a bold declaration in the Arabian Gulf, mimicking Dubai.

In addition, it is clear that the Burj-al-Arab hotel is without uncertainty is the business logo of the Dubai vision, this spinnakershaped hotel is an international phenomenon, Promptly identifiable, It seems on just about all reminder the city has to proposal besides an image directly related with ambition and prosperity [11].

\section{B- Emirates Twin towers:}

It is clear that, the project of Emirates is a twin tower growth in Dubai, the plan form the towers are triangular, through a face dimension of around $50-54 \mathrm{~m}$, and it can be consider that one of the United Arab Emirates. Also, the higher office tower has 52 floors and increases $355 \mathrm{~m}$ above ground level, while the smaller hotel tower is $305 \mathrm{~m}$ tall. These towers are further than double the height of the nearby world trade Centre that was previously the highest building in Dubai. On the other hand, the foundation scheme for both of the towers complicated the usage of Greatdiameter piles, in combination with a raft. Furthermore, a piled raft was used as a foundation system for both of the towers [15].

Additionally, the towers was planned to offer efficiency and unequaled flexibility to a variety of businesses, it is rising around 1,165 feet to its highest point, the higher of the twotower growth and offers an appropriate atmosphere for Dubai's developing High Tech sector as shown in figure 10. Furthermore, it can be seen that the vision for Emirates Towers was to generate an advanced technical substructure that could be ascendable to building management technology developments and future knowledge [9].

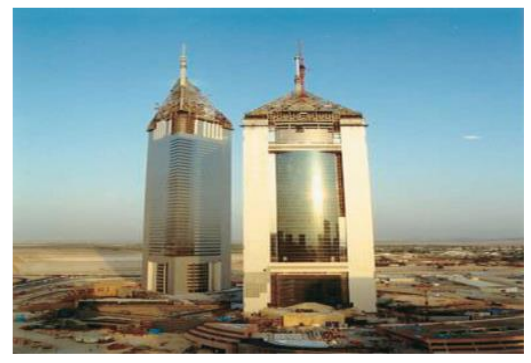

Figure10: the Emirates Twin Towers soon after completion of construction.

'Middle East's office and hotel compound offers efficiency to inhabitants and unequalled flexibility."

On the other hand, the project of Emirates complicated adjacent interaction between geotechnical designers and the structural in scheming piled raft foundations for both two important high-rise structures and complex [15]. But, in regarding to the project challenges, it is applying an advanced technological infrastructure which is climbable for future expansions, also providing integrations and the latest available technologies to safeguard Emirates Tower's competitiveness, whereas ensuring a quality building environment [11].

Furthermore, In terms of technology offers a competitive edge: It can be notice that in emerging recreation destinations and traveller, competitors are frequently distinguished founded on the modern technology available in convention centers and hotels. In fact, it can be say that Emirates Towers is a new business center and hotel in Dubai besides United Arab Emirates in the Persian Gulf as well. More over

, it is an outstanding adding to the Dubai skyline and among the highest buildings in the Middle East [11].

On the other hand, in this project used Johnson Controls' Technology Contracting approach, guest-related systems, property management, fire, telecommunications, security, and even multimedia applications can be knotted together [11]. 


\section{C- Conclusion case study 2}

From the two building design products mentioned at the above, researcher has managed to summarize the key components for originality in the building such as: scale, recognizable forms, long-term impressions, relating to past (history of the place), attracting attention, iconic, and symbolic.

Therefore, researcher discovered that:

1-Dubai has many of these original buildings, but Burj-al-Arab stands out more than others in the whole region. There are other new buildings, which symbolize other characteristics of Dubai such as the Emirates Tower of high-flying business and Burj Khalifa's marketable slant which is the tallest tower in the world currently, but the Burj-alArab stands out as it was "the city's first attempt to redefine itself in the modern age [25].

2-The Burj-al-Arab's distinctive shape and form allows it in order to act as a really memorable symbol of numerous aspects of Dubai's character and heritage, most notably Dubai's growing tourism industry and the transition to the future of it. But the Emirates Towers do not have this distinctive form.

3-Burj-al-Arab is a living example of economic growth and success that found through tourism and it influx and triggered of hotel developments in the city, by knowing that Dubai had become a new and reliable place to develop. It has improved Dubai's tourist industry and became a fortune for it as well as developing the general image of Dubai it became a more attractive place for investment [11].

On the other hand, it can be seen clearly that Emirates Tower's image of high-flying business is a huge twin tower development in the city of Dubai; the towers were designed to give unrivaled and efficient range of businesses,

Moreover, they have used the most advanced tools and technology network as well as a fully integrated metises constructional building automation and engineering system by Johnson Controls Inc. Additionally, the vision for the Emirates Towers were to make a country-of-the-art and technological infrastructure. This can be scalable and appropriate for the future building management technology developments and information [9].

\section{Conclusions}

Through the literature reviews and case studies, as well as, according to researchers experience and backgrounds that, there is no particular definition for originality, each source defines it differently. Also everyone has different point of view towards originality but, it can have a similar meanings.

Therefore researcher concluded that:

1. It can be said that everything has it is own originality in its place, but also there might be things more original than another according to its characteristics and the criteria for measuring and assessing originality. In other words, It can be compared every two design product through this method or putting some criteria.

2. We cannot copy or repeat any think $100 \%$, there are some differences that belongs to your speciality or individuality. Finally, originality can be defined as the first idea for this subject. Also, sometimes using old ideas and presenting in a new way by changing and adding something 
new. For instance, many astronauts travelled to the moon but, Neil Armstrong was the one who walked on the moon on July 16, 1969.

3. Another example is Michael Angelo, who proposed the church for the first time in history. That shows originality means proposing an idea for the first time.

4. Originality does not stand against classic or tradition but, it gives it new life.

5. In order to have originality in architecture it must be learned from great architect and comparing our works with their works.

6. To increase the original idea, the architect should have a historical sense (the sense of timelessness and temples together); this is not only giving us a perception of the past, also understanding the present ideas. Moreover, defining their building behind their time or their generation.

7. In order to enrich the personality of the architect he or she must render and adjust him/ her to the present project that needs to be done.

8. Researcher concluded that, most of post modernisms buildings are original, because they are innovative, creative and iconic in their designs. Also they reflect their time period. Additionally, their buildings have special characteristics that have their own identity. Moreover what has been said reflects in other iconic styles such as: Frank Gerry's Guggenheim museum in Bilbao, Spain. And opera house. Also Eiffel tower that has become a global cultural icon of France and one of the most recognizable structural buildings in the world. The tower is the tallest building in Paris and the most-visited paid monument in the France.

\section{Findings and conclusions regarding to the measurement of originality in architecture:}

Depending on this research, researchers experience, educational background, human cognition and visual perception researcher discovered that it's a combination of different factors that (makes a building original). For a building to be considered as original must include a number of points as shown below:

It has to make an impact on its context, through gaining a reputation it should became a famous, symbolic and more attractive to society for example it should be known to both people who see the building (pragmatic sense) and those who don't see it.

In terms of form of building, the design has to be both memorable and distinctive, easy to drawing, special, recognizable and aesthetically must be interesting and amazing (material, color... and so on .)

1. A structure is also considered as iconic when it represents the symbol of a country. Also, iconographic symbolism meaning that a structure is architecturally unique and brilliant. In addition, value that should involve (major investment). Moreover, viability (located in a business centre), innovation, reception and creativity. For example Tom Wright the architect who was behind the Burj-al-Arab claims that (if a building drawn simply) it will be recognizable and then it can be considered as original. 
2. It can also include a concept and there should be an innovative idea behind it (design concept and ideology), also there should be an iconographic symbolism (a strong meaning behind the building).

3. The place of the building there needs to be a (relation between the building and its place). This shows that shows the building has a strong relationship with history of the area, culture and present day (design concept and ideology).Therefore, if the same building or same form implemented in different place, it cannot be called original or advertising of nationality.

4. The relation of the shape (form) with the place, which means there is a link between the building and its surroundings, for example: the shape, colour, and all its characteristics are suitable with the surrounding area. The way of utilizing the design and the shape suits the place and arrangement of elements with other.

5. Challenging all the other structural buildings in the world, on the regional level as well as the local level for its time. In addition, it has been to be known and became famous as well. Also it should stay in the history for a long time.

6. The application of the latest science and technology, for instance there are many buildings that during construction they used classic and old technology, but the one that used the latest technology to construct becomes original.

7. The design is the first of its kind which is built for the first time and it is totally different with the rest of the other ones and it is not common form and design. On the other hand, it becomes something different and attracts people such as: Burj al Arab in Dubai or Opera House in Sidney. Also, in India there are some examples of architecture that have their special characteristics that makes them the wonders of the world even though it had been made centuries ago such as Taj Almahal.

8. Some times by deriving from nature, things can be designed such as green color and wood ....etc.) Or innovating in anything for the first time.

\section{References:}

[1] -Baker, D (2012), Architect Gehry on creativity, originality and getting one's way in the end, viewed 28 may 2013

http://news.yale.edu/2012/04/13/architect-gehrycreativity-originality-and-getting-one-s-way-end

[2] -Bruce Goff, (1968). Originality and Architecture, P. 1, viewed 20.june.2013.

http://www.bruce-goff-film.com, down loaded 20 june.2013at http://www.google.com.tr/\#sclient=psy-

[3]-Bicknell, On Originality, viewed 23 may 2013, http://luciensteil.tripod.com/katarxis02-1/id2.html

[4]-Bawa, On Originality, viewed 23 may 2013.

[5]- Erin (2000), Originality does not mean thinking something that was never thought before; it means putting old ideas together in new ways, viewed 20 may 2013 ,

http://www.urch.com/forums/gre-analysis-issue/4665173-originality-does-not-mean-thinking-somethingne.html.

[6]-Essay Forum (2013), Originality means putting old ideas together in new ways, viewed 20 may 2013, http://www.essayforum.com/essays-term-papers1/originality-means-putting-old-ideas-together-newways-6675/. 
[7]-EunKyong Baek (2007)," Creativity and What is creativity anyway "CREEM Creativity Work shop, In De Montfort, University, on 17.10 .2007 . Viewed 23 may 2013,

http://www.youtube.com/watch?v=fqshc2PWIo\&feature $=$ relmfu.

[8] -Itewi, M. (2007). "Towards a Modern Theory of Islamic Architecture ", Australian Journal of Basic and Applied Sciences, p.153-155, vol. 1(2) , ISSN 19918178 , Tafila , Jordan.

[9]- Johnson Controls, Inc.(2008), EMIRATES TOWERS. Dubai, United Arab Emirates, p.1-4., Printed in USA CSST-08-039, printed on recycled paper, Metasys ${ }^{\circledR}$ is a registered trademark of Johnson Controls, Inc.,

www.johnsoncontrols.com.

[10] - Lobito,W. , Fab chairs \& other innovative designs, , viewed 10 June 2013,

http://pinterest.com/pin/45950858669374408/.

[11]- Ludbrook, M., How influential is iconic architectureto the increase of business and tourism in dubai. P. 6-8. , UNIT 320.

[12]-Moyle and Kathryn (2010). Building Innovation: Learning with technologies, p.11-15, ISBN: 9780864318619, Information technology, Australia.

[13]-Newell, B.C.(2010). Independent creation and originality in the age of imitated reality: a comparative analysis of copyright and database protection for digital models of real people , P. 104,111., California ,UAS.

[14]-Neagu, C. (2006), The Issue of originality and influence in architecture, viewed 28 may 2013, http://www.geocities.com/rlcstr/arch524/cristinan\#_f tn5..

[15]-Poulos,H.,G. and Davids, A.,J.(2005), Foundation design for the Emirates Twin Towers, Dubai,p.1-14, NRC Canada.

[16]-Palladio, A., On Originality, viewed 23 may 2013, http://luciensteil.tripod.com/katarxis02-1/id2.html

[17]-Rachelelizaguthrie (2009) Re-presenting Art Measuring: Originality, viewed 21 may 2013,

http://rachelelizaguthrie.wordpress.com/2009/09/24/representing-art-measuring-originality/

[18]-Runco, M. A. (2009).Parsimonious creativity and its measurement, P.393-400, Torrance Creativity Center, Athens.
[19]-Todayinsci (2013), Originality in Architecture, viewed 21 may 2013,

http://todayinsci.com/stories/story024.htm

[20]-Terry Q. , On Originality, viewed 23 may 2013,

http://luciensteil.tripod.com/katarxis02-1/id2.html

[21]-Tangle Creations, Pierandrei Associati\& Richard X. Zawitz (2013), Infinity Furniture Collection by Tangle Creations, viewed 10 June 2013,

http://www.yatzer.com/Infinity-Furniture-Collectionby-Tangle-Creations-Richard-X-Zawitz

[22] - Vidalis, M. A. (2010), Architecture - Is Originality Always Feasible Or Desirable? (Notes on the Avant-Garde), viewed 20 may 2013 ,

http://ezinearticles.com/?Architecture---Is-OriginalityAlways-Feasible-Or-Desirable?-(Notes-on-the-AvantGarde)\&id=4564261.

[23]-William \& Mary Law School Scholarship Repository (1993)." Rethinking Originality ", Russ VerSteeg, P. 818,824, 873, vol 34(3), downloaded at http://scholarship.law.wm.edu/wml on 21.may.2013.

[24]- Wright, T. (2000). Retrieved November 2010, from Tom Wright Design:

http:/ / www.tomwrightdesign.com.

[25]-Barrett, R. (2009). Dubai Dreams: Inside the kingdom of Bling. Boston: Nicholas Brealey Publishing.

[26] -Abdelmonem, M. G. (2017)"Architectural and urban in the digital age: dilemmas of authenticity, originality and reproduction", Archnet-IJAR: International Journal of Architectural Research, Vol. 11 - No. 3, Pp. 5-15. 